\title{
Quintiliano e a gramática antiga ${ }^{1}$
}

\author{
MARCOS A. PEREIRA \\ Universidade Estadual de Campinas
}

RESUMO: O trabalho comenta os "capítulos gramaticais" do primeiro livro da Institutio oratoria de Quintiliano, onde o autor trata das funções do mestre de Gramática e aponta a disciplina como auxiliar da Retórica na formação do antigo orador, sendo posterior sua independência como saber que visava à descrição ou sistematização autônoma de fenômenos da linguagem. Pretende-se focalizar o próprio conteúdo da obra de Quintiliano, cujo papel na história dos estudos posteriores sobre o tema costuma ser ignorado.

PALAVRAS-CHAVE: Institutio oratoria; Gramática; Retórica; Quintiliano.

Embora seja longa a tradição de estudos clássicos e gramaticais entre nós, são poucos os trabalhos que apresentem atualmente uma análise específica do pensamento legado pelos antigos sobre a linguagem. Na verdade, nem mesmo as várias publicações existentes em português que tratam da história do pensamento sobre a linguagem costumam dedicar muito espaço à chamada Antigüidade Clássica ${ }^{2}$. No que diz respeito, especificamente, ao tratamento dado pelos romanos a questões de linguagem, a tônica dos trabalhos existentes, com raras exceções, costuma ser a de considerá-los meros reprodutores daquilo que os gregos pensaram e disseram sobre o assunto ${ }^{3}$.

Em sua História da Lingüística (cuja primeira edição, publicada em inglês, data de 1962), Mattoso Câmara aponta sete maneiras de estudar a linguagem numa comunidade humana que, de acordo com seu enfoque, poderiam ser chamadas "estudo do certo e do errado", "estudo da língua estrangeira”, "estudo filológico da linguagem”, "estudo lógico da linguagem", "estudo biológico da linguagem", "estudo histórico da linguagem" e "estudo descritivo da linguagem". As três primeiras abordagens fariam parte do que o autor chama "Pré-Lingüística", pois se fundam elas menos sobre a própria linguagem que sobre a busca de adequação de um dado sistema lingüístico àquele que seria seu "objetivo primeiro", a comunicação entre os homens, bem como sobre o estudo das culturas e literaturas expressas em tal sistema. Em seguida, viriam as abordagens "paralingüísticas", que estariam ainda interessadas num certo uso da linguagem, qual seja o "filosófico" (ou "lógico"), e nos fundamentos biológicos de seu uso pela espécie humana. A "Lingüística propriamente dita" só teria início com as investigações de caráter histórico sobre a linguagem, no século dezenove, em que se buscou compreender a origem e a evolução dos sistemas lingüísticos empregados no mundo, e com as de caráter descritivo, em que se 
procurou mostrar seu funcionamento num dado momento e espaço, sem referência a seu processo evolutivo.

Na Antigüidade, teriam prevalecido os estudos "do certo e do errado", "filológico" e "filosófico", sendo que na Índia, particularmente, os dois primeiros parecem ter-se desenvolvido bastante, com a intenção precípua de preservar a estrutura de textos sagrados. Graças, ao menos em parte, a trabalhos como os do gramático Panini (séc. IV a.C.), por exemplo, é que eles puderam chegar até os dias atuais, dando a conhecer a língua em que foram produzidos (o sânscrito), cuja "descoberta", por eruditos do século XVIII, teria mesmo importância no posterior desenvolvimento da Lingüística como ciência. Na Grécia, desenvolveram-se tanto os estudos "filológicos", no trabalho de edição e exegese das obras divulgadas a princípio oralmente, de geração a geração, como as de Homero, quanto os estudos "filosóficos" sobre a linguagem. Nesse pormenor, interessaram-se os gregos, basicamente, por saber se a linguagem era fruto de uma espécie de convenção entre os homens ou estava necessariamente ligada às coisas das quais se pode falar através dela, bem como pela categorização gramatical e pela etimologia (entendida então como a busca do "verdadeiro significado" veiculado pelas palavras e, em última instância, da origem da linguagem).

Ainda segundo Mattoso Câmara (1983), os estudos de linguagem realizados no período clássico pelos autores latinos estiveram, por sua vez, mais centrados no que ele denomina "estudo do certo e do errado", motivados como foram também por uma preocupação dos romanos com a implantação do latim nas suas colônias. Assim, se em sua investigação sobre a natureza e a origem da linguagem os gregos foram primeiro filósofos, os romanos teriam sido, desde muito cedo, gramáticos, emprestando daqueles as categorias desde então utilizadas na descrição e análise das línguas. Pondo de parte as especificidades da reflexão romana sobre a linguagem, incorre-se também aí no preconceito de considerar que o trabalho dos autores latinos consistiu num simples decalque daquele realizado pelos gregos. É na tentativa e com o ensejo de contribuir para uma reavaliação do trabalho desenvolvido pelos romanos sobre a linguagem que optamos por tratar de um texto não muito conhecido ou divulgado, mas de não pequena importância quando de seu surgimento e mesmo para épocas posteriores: os capítulos referentes à Gramática presentes na Institutio oratoria ("A educação oratória') de Marco Fábio Quintiliano (ca. 30-96 d.C.).

A importância do autor, não apenas para seu tempo como para a história cultural do Ocidente, é unanimemente reconhecida ${ }^{4}$. Advogado e mestre de Tácito e Plínio o Jovem, entre outros, Quintiliano apregoa a velha fórmula de Catão na apresentação do seu método: o bom orador é, antes de mais nada, "um homem de bem, experimentado na arte de discursar" (XII, 1: uir bonus dicendi peritus). No primeiro livro da Institutio, considerado verdadeiro tratado pedagógico (cf. Paratore, 1987, p. 700), o autor procura justamente delinear a figura desse orador, cuja formação na antiga Roma principiava muito cedo. Fala, nos capítulos 4-9, do papel do mestre de Gramática, aquele que, tendo já a criança dominado os princípios da leitura e da escrita, iria guiá-la no conhecimento da língua dos autores que constituíam o patrimônio cultural da época ${ }^{5}$. Ao mesmo tempo que a discute, Quintiliano faz então uma apresentação da Ars grammatica latina, na qual trata questões relativas aos diferentes níveis da análise gramatical, passando pela etimologia, pela controvérsia entre analogistas e anomalistas, bem como por considerações sobre o valor da leitura e os métodos de ensino então em voga. 
Referido à Antigüidade, o termo grammaticus, de origem grega, recobre, como se depreende da própria leitura do texto de Quintiliano, um sentido não de todo coincidente com o que lhe é atribuído hoje. Era apenas uma de suas funções ministrar conhecimentos relativos ao "bom uso" da linguagem, entendido como o uso que dela faziam os poetas, oradores e historiadores; aqueles que, em suma, haviam empregado a língua de forma especialmente elaborada, pelo que os autores passaram a ser tomados como modelos, donde a necessidade de "imitá-los". Resta examinar em que se fundava - para seu discípulo, o futuro orador, no caso -, tal necessidade de "imitar" os escritores no uso que faziam da língua.

Como informa Kennedy (1962, p. 145):

"o bom orador, como ideal de vida humana, pode não se mostrar imediatamente simpático aos olhos dos leitores modernos, mas precisamos nos dar conta de que a palavra pronunciada significou para a Antigüidade muito do que a razão significou para o século dezoito, de que ela envolvia tanto o poder do pensamento humano e a posição do homem na sociedade, como envolvia, ademais, criatividade e poder pessoal".

Noutros termos, o discurso - artisticamente elaborado - possuía uma importância considerável dentro da vida do homem culto e do homem de Estado. Ora, quem, senão os poetas e escritores em geral, eram então os responsáveis pela construção de um discurso que mobilizasse de tal modo a linguagem para ensinar-comover-deleitar - para encantar, enfim? E o orador devia, justamente, encantar - para persuadir - no seu uso da linguagem, que devia primar, portanto, por aquelas qualidades inerentes ao texto artístico. Seu trabalho era uma arte, dominada por regras que constituíam o corpo daquilo que se chamou Retórica na Antigüidade, entendida em Quintiliano não apenas como a "arte de bem dizer", mas também como um conjunto de normas que governava o uso da linguagem pelo orador.

Nesse contexto deve ser compreendida a Gramática na Antigüidade: ela era a primeira das chamadas artes liberais e aquela disciplina sem a qual não se podia, pelas razões referidas, fazer o orador, o qual devia, antes mesmo de saber discursar, mobilizando todos os recursos expressivos da língua para convencer - como era também seu papel-, conhecer esse instrumento. E só se podia conhecê-la, então, naqueles textos em que ela se atualizava melhor. Cabia, portanto, ao mestre encarregado do ensino da disciplina gramatical tornar o futuro orador capaz de empregar a linguagem de modo apropriado a partir daqueles textos onde ela melhor se realizava, cuja explicação também era sua incumbência - a Gramática era a scientialars bene loquendi e poetarum enarratio.

É como auxiliar, portanto, da Retórica e da Oratória que essa Gramática deve ser encarada no texto de Quintiliano. Sua independência como disciplina que visava à "descrição" ou antes à sistematização, autônomas, de fenômenos de linguagem, só pôde ser posterior às investigações realizadas pelos gregos vários séculos antes de nossa era - os quais, tendo em vista necessidades ditadas pela situação helenística, transformaram a Gramática em disciplina normativa (cf. Neves, 1987) -, bem como ao serviço por ela prestado à Retórica, que tamanha importância teve em Roma (cf. Mattos e Silva, 1989, p. 19s). E é exatamente assim que ela figura no trabalho de Quintiliano, que, de resto, não é apenas um 
tratado de Retórica, mas sobretudo pedagógico. De fato, é a figura do educador que ressalta no primeiro livro da Institutio oratoria, onde o autor descreve a educação daquele que se desejava fazer orador, para quem o estudo sério da Gramática, como disciplina que devia conduzir ao conhecimento da língua dos autores representativos para a época, era imprescindível.

Nos capítulos 4-9 do livro I da Institutio, Quintiliano se dirige aos grammatici, "aconselhando", como diz, "aqueles que vão ensinar" (Instit. orat. I, 4, 17). E qual é, em resumo, o conteúdo de tal "aconselhamento"? Quintiliano procura, em primeiro lugar, defender o ensino/estudo sério da Gramática como meio necessário tanto para uma intelecção e uma fruição válidas das obras, sobretudo "clássicas", daquilo que chamaríamos de literatura grega e latina, quanto para a própria formação do orador ${ }^{6}$. Em segundo, discutir o papel do mestre de Gramática e de sua disciplina, passando em revista os tradicionais níveis gramaticais encontráveis nos "tratados" da época, apontando falhas em determinados pontos, propondo soluções em outros, centrando-se no efetivo uso da língua pelos grandes autores. Não cabe exigir dos antigos uma preocupação maior com a língua falada comum do cotidiano, muito simplesmente porque não era a ela que cabia figurar nos discursos, e não é dela que tratou a Gramática antiga (cf. Versteegh, 1986).

O trabalho de Quintiliano representa mesmo uma tentativa de reafirmar a importância da disciplina gramatical, tendo em vista a formação do orador, interesse central da Institutio. Ao que parece, a obra aponta para um momento de crise na história da Gramática em Roma, certamente devida, ainda que apenas em parte, ao trabalho mal exercido por alguns grammatici. Lembrem-se, a título de exemplo, as críticas de Sêneca, Juvenal e Aulo Gélio, que apontam para um declínio no prestígio daqueles profissionais, que sempre o procuraram extrair do conhecimento de uma tradição que se esforçavam por passar adiante (cf. Kaster, 1986).

Em resumo, ressalta da exposição de Quintiliano um senso de conveniência, de aplicabilidade do conhecimento e, acima de tudo, de respeito tanto pelo educando quanto pelo trabalho de seu educador. Poder-se-ia, talvez, resumir com suas próprias palavras sua visão do ensino/estudo da Gramática, eivado, já à época, de elementos por assim dizer nem sempre indispensáveis e, muitas vezes, é verdade, colocado nas mãos de profissionais nem sempre zelosos de seu ofício ${ }^{7}$. Se, por um lado, como afirma o autor, “[...] não [...] parece desprovido de graça dizer que é uma coisa falar latim, outra falar gramatiquês" (Instit. orat. I, 6, 27: ... mihi non inuenuste dici uidetur, aliud esse Latine, aliud grammatice loqui), também é verdade que "[...] nada do que diz respeito à Gramática será nocivo, senão aquilo que é inútil” (I, 7, 34: ... nihil ex grammatice nocuerit, nisi quod superuacuum est). E mais: "Tais matérias não constituem embaraço aos que passam por elas, mas aos que se detêm nelas" (I, 7, 35: Non obstant hae disciplinae per illas euntibus, sed circa illas haerentibus). "Por isso, contarei entre as virtudes do mestre de Gramática o desconhecimento de algumas coisas" (I, 8, 21: Ex quo mihi inter uirtutes grammatici habebitur aliqua nescire).

A obra de Quintiliano não foi um trabalho isolado produzido pela erudição de sua época, tendo mesmo vindo a servir de modelo de pedagogia escolar tanto no que diz respeito ao como quanto no que diz respeito ao quê ensinar. Em Quintiliano, de fato, se buscou um paradigma na elaboração de programas educacionais, especialmente a partir do Renascimento (cf. Carpeaux \& Neves, 1983, p. 9528; Kennedy, 1962, p. 142), quando não apenas 
os estudos clássicos floresceram, mas também o interesse pelas novas línguas da Europa, bem como pelo seu ensino.

A concepção de línguallinguagem e de Gramática com a qual lidamos e da qual somos herdeiros principiou, é verdade, por considerar os fenômenos lingüísticos a partir de uma língua até certo ponto "artificial", porque marcada pela escrita (cf. Lyons, 1979, p. 9) mais precisamente, a língua daqueles autores, especialmente os poetas clássicos, que legaram à posteridade monumentos de grande valor artístico, tomados por isso mesmo como "modelos". De qualquer maneira, em seu conjunto, foram esses estudos, iniciados pelos gregos como uma reflexão sobre a natureza da linguagem, que passaram à posteridade, embora bastante modificados - em grande parte por obra de autores latinos - como a busca do estabelecimento de uma norma, que visava ao mesmo tempo sobrepujar outras tantas normas possíveis e fixar um modelo, abstrato, que a elas pudesse servir de referência, procurando escapar às mudanças operadas pelo tempo sobre as línguas, com todas as conseqüências daí decorrentes.

A Institutio oratoria de Quintiliano, sem ter por meta constituir propriamente um tratado gramatical, tira sua importância, dentre outras coisas, exatamente do fato de documentar essa tradição de estudos gramaticais em seus inícios, possibilitando-nos, assim, o contato com o que por primeiro se produziu no Ocidente, em língua latina, sobre doutrinas gramaticais, raiz de toda a reflexão posterior sobre língua e linguagem ${ }^{8}$.

\section{Notas}

1 - Este texto teve uma versão, intitulada "Os capítulos gramaticais da Institutio oratoria de Quintiliano", que figura nos Anais do $2 .^{\circ}$ Encontro do Círculo de Estudos Lingüísticos do Sul CelSul, publicada em forma de CD-ROM (Florianópolis, 1999).

2 - Lyons (1979) e Mattoso Câmara (1983), referidos aqui, dedicam espaço à Antigüidade Clássica em seus manuais, fornecendo muitas informações valiosas. No entanto, das várias "Histórias da Lingüística" por nós conhecidas, apenas Robins (1983) inclui um estudo mais aprofundado da reflexão antiga sobre a linguagem. Conferir também, sobre o tema, Della Casa (1987, p. 41-91).

3 - Tal é o caso, especialmente, de obras como a de Mounin (1970, p. 95), que afirma textualmente: "Roma merece um capítulo numa história da lingüística [...] bem menos por ter produzido que por haver transmitido".

4 - Cousin (1975: XCIV), cuja edição do texto de Quintiliano seguimos no trabalho, considera-o mesmo "um dos mestres das formas de expressão do pensamento ocidental e o 'instituidor' da retórica universal".

5 - Sobre a educação na Antigüidade Greco-Romana, conferir o conhecido trabalho de Marrou (1955). Rocha Pereira (1984) trata especificamente da antiga educação romana.

6 - Não é de outra coisa, senão da formação do orador (veja-se o próprio título da obra de Quintiliano), que se trata na Institutio. O trabalho do antigo grammaticus (em suma, ensinar a língua literária e explicar os poetas clássicos) estava situado antes daquele a ser realizado pelo rhetor, a quem o jovem romano era confiado quando já dominasse perfeitamente os meios de expressão da linguagem culta.

7 - Carcopino (1990), por exemplo, faz uma avaliação negativa do trabalho desenvolvido pelos grammatici da antiga Roma. Mas foi muito cedo que eles tiveram seus detratores, como Sêneca 
e Juvenal, à época de Quintiliano. O próprio Erasmo, no século XVI, ainda os criticaria pelos mesmos motivos.

8 - Essa é, de fato, a história da Gramática, tradicionalmente considerada, com seu caráter eminentemente escolar e todos os problemas, por demais conhecidos, que ela apresenta. O que se procura fazer, aqui, é apontar para sua natureza e para a razão de sua valorização na Antigüidade Clássica.

\section{Referências bibliográficas}

CÂMARA Jr., Joaquim M. História da lingüística. Trad. Maria do Amparo B. Azevedo. 3. ed. Petrópolis: Vozes, 1983.

CARCOPINO, Jérôme. Roma no apogeu do império. Trad. Hildegard Feist. São Paulo: Companhia das Letras/Círculo do Livro, 1990.

CARPEAUX, Otto M. \& NEVES, M. C. B. "Quintiliano”. In: Enciclopédia Mirador Internacional. São Paulo/Rio de Janeiro: Encyclopaedia Britannica do Brasil, 1983. vol. 10, p. 9528.

DELLA CASA, Adriana. "La Grammatica". In: AA.VV. Introduzione allo studio della cultura classica. Milão: Marzorati, 1987. vol. 2, p. 41-91.

KASTER, Robert A. "Islands in the stream: the grammarians of late antiquity". Historiographia Linguistica. Amsterdã/Filadélfia, vol. 3, n. 2/3, p. 323-432, 1986.

KENNEDY, George A. An estimate of Quintilian. American Journal of Philology. Baltimore, vol. 83, n. 2, p. 130-146, 1962.

LYONS, John. Introdução à lingüística teórica. Trad. Rosa V. M. Silva e Hélio Pimentel. São Paulo: Nacional/EDUSP, 1979.

MARROU, Henri-I. Histoire de l'éducation dans l'antiquité. 3. ed. Paris: Seuil, 1955.

MATTOS E SILVA, Rosa V. Tradição gramatical e gramática tradicional. São Paulo: Contexto, 1989.

MOUNIN, Georges. História da lingüística: das origens ao século XX. Trad. F. J. Hopffer Rêgo. Porto: Despertar, [1970].

NEVES, Maria Helena de Moura. A vertente grega da gramática tradicional. São Paulo/ Brasília: HUCITEC/UnB, 1987.

PARATORE, Ettore. História da literatura latina. Trad. Manuel Losa. Lisboa: Fundação Calouste Gulbenkian, 1987.

PEREIRA, Marcos A. De officio grammatici: os capítulos gramaticais da Institutio oratoria de Quintiliano e o papel do mestre de gramática. Dissertação de Mestrado. São Paulo: FFLCH/USP, 1997.

QUINTILIEN. Institution oratoire. Ed. Jean Cousin. Paris: Belles Lettres, 1975. 7 v.

ROBINS, Robert Henry. Pequena história da lingüística. Luiz M. M. de Barros. Rio de Janeiro: Ao Livro Técnico, 1983.

ROCHA PEREIRA, Maria Helena da. Estudos de história da cultura clássica. Vol. II: Cultura Romana. Lisboa: Fundação Calouste Gulbenkian, 1984. 
VERSTEEGH, Kees. Latinitas, Hellenismos, Arabiyya. Historiographia Linguistica. Amsterdã/Filadélfia, vol. 3, n. 2/3, p. 425-448, 1986.

PEREIRA, Marcos A. Quintilian and ancient grammar. Classica, São Paulo, 13/14, p. $367-$ $373,2000 / 2001$.

ABSTRACT: The paper comments on the grammatical chapters in Book I of Quintilian's Institutio oratoria, where the author deals with the duties of the Grammar teacher, facing the discipline as an auxiliary to Rhetoric in the education of the ancient orator. Only after its service to Rhetoric, indeed, Grammar became an independent discipline that aimed properly for presenting an analysis or description of a language. The work intends to focus briefly on the specific content of the grammatical chapters in Quintilian, whose role in the history of linguistic studies is hardly stressed. KEYWORDS: Institutio oratoria; Grammar; Rhetoric; Quintilian. 